\title{
Dysregulation of miR-381-3p and miR-23b-3p in skeletal muscle could be a possible estimator of early post-mortem interval in rats
}

\author{
Vanessa Martínez-Rivera ${ }^{1}$, Christian A. Cárdenas-Monroy ${ }^{1}$, Oliver Millan-Catalan ${ }^{2,3}$, Jessica Gonzalez-Corona ${ }^{1}$, \\ Sofia Huerta-Pacheco ${ }^{4}$, Antonio Martinez-Gutierrez ${ }^{2}$, Alexa Villavicencio-Queijeiro ${ }^{1}$, Carlos Pedraza-Lara ${ }^{5}$, \\ Alfredo Hidalgo-Miranda ${ }^{6}$, María Elena Bravo-Gómez ${ }^{7}$, Carlos Pérez-Plasencia ${ }^{2,3}$, Mariano Guardado-Estrada ${ }^{\text {Corresp. }}$ \\ ${ }^{1}$ Laboratorio de Genética de la Licenciatura en Ciencia Forense, Facultad de Medicina, Universidad Nacional Autónoma de México, Ciudad de México, \\ Ciudad de México, México \\ 2 Laboratorio de Genómica, Instituo Nacional de Cancerologia, Ciudad de México, Ciudad de México, México \\ 3 Laboratorio de Genómica, Unidad de Biomedicina, Facultad de Estudios Superiores Iztacala, Universidad Nacional Autónoma de México, Ciudad de \\ México, Ciudad de México, México \\ ${ }^{4}$ Cátedras CONACYT - Ciencia Forense, Facultad de Medicina, Universidad Nacional Autónoma de México, Ciudad de México, Ciudad de México, México \\ 5 Laboratorio de Entomología de la Licenciatura en Ciencia Forense, Facultad de Medicina, Universidad Nacional Autónoma de México, Ciudad de México, \\ Ciudad de México, México \\ 6 Laboratorio Genómica del Cáncer, Instituto Nacional de Medicina Genómica, Instituto Nacional de Medicina Genomica, Ciudad de México, Ciudad de \\ México, México \\ 7 Laboratorio de Toxicología de la Licenciatura en Ciencia Forense, Facultad de Medicina, Universidad Nacional Autónoma de México, Ciudad de México, \\ Ciudad de México, México \\ Corresponding Author: Mariano Guardado-Estrada \\ Email address: mguardado@cienciaforense.facmed.unam.mx
}

Background. The post-mortem interval (PMI) is the time elapsed since the dead of an individual until the body is found, which is relevant for forensic purposes. The miRNAs regulate the expression of some genes; and due to their small size, they can better support degradation, which makes them suitable for forensic analysis. In the present work, we evaluated the gene expression of miR-381-3p, miR-23b-3p, and miR-144-3p in skeletal muscle in a murine model at the early PMI.

Methods. We designed a rat model to evaluate the early PMI under controlled conditions. This model consisted in 25 rats divided into five groups of rats, that correspond to the $0,3,6,12$ and 24 hours of PMI. The $0 \mathrm{~h}$-PMI was considered as the control group. Muscle samples were taken from each rat to analyze the expression of miR-381-3p, miR-23b-3p, and miR-144-3p by quantitative RT-PCR. The gene expression of each miRNA was expressed as Fold Change (FC) and compared among groups. To find the targets of these miRNAs and the pathways where they participate, we performed an in-silico analysis. From the gene targets of miR-381-3p identified in the silico analysis, the EPC1 gene was selected for gene expression analysis by quantitative RT-PCR in these samples. Also, to evaluate if miR-381-3p could predict the early PMI, a mixed effects model was calculated using its gene expression.

Results. An upregulation of miR-381-3p was found at $24 \mathrm{~h}-\mathrm{PMI}$ compared with the control group of $0 \mathrm{~h}$ $\mathrm{PMI}$ and $(\mathrm{FC}=1.02 \mathrm{vs} . \mathrm{FC}=1.96 ; p=0.0079)$. This was the opposite for miR-23b-3p, which had a downregulation at $24 \mathrm{~h}-\mathrm{PMI}$ compared to $0 \mathrm{~h}-\mathrm{PMI}$ ( $\mathrm{FC}=1.22$ vs. $\mathrm{FC}=0.13 ; p=0.0079$ ). Moreover, the gene expression of miR-381-3p increased throughout the first $24 \mathrm{~h}$ of PMI, while it was the opposite for miR-23b-3p. The targets of these two miRNAs, participate in biological pathways related to hypoxia, apoptosis, and RNA metabolism. The gene expression of EPC1 was found downregulated at 3 and $12 \mathrm{~h}$ of PML wherazs it ramainod unchangad at 5 he and $24 \mathrm{~h}$ of PMI. Using a multivariate analysis, it was possible 
to predict the FC of miR-381-3p of all but $6 \mathrm{~h}-\mathrm{PMI}$ analyzed PMIs.

Discussion. The present results suggest that miR-23b-3p and miR-381-3p participate at the early PMI, probably regulating the expression of some genes related to the autolysis process as EPC1 gene. Although the miR-381-3p gene expression is a potential estimator of PMI, further studies will be required to obtain better estimates 


\section{Dysregulation of miR-381-3p and miR-23b-3p in}

2 skeletal muscle could be a possible estimator of early

3 post-mortem interval in rats.

4

5

6

$$
7
$$

\section{Vanessa Martínez-Rivera ${ }^{1}$, Christian A. Cárdenas-Monroy ${ }^{1}$, Oliver Millan-Catalann ${ }^{2,3}$, Jessica} González-Corona $^{1}$, Sofia Huerta-Pacheco ${ }^{4}$, Antonio Martinez-Gutierrez ${ }^{2}$, Alexa VillavicencioQueijeiro $^{1}$, Carlos Pedraza-Lara ${ }^{6}$, Alfredo Hidalgo-Miranda ${ }^{5}$, María Elena Bravo-Gómez ${ }^{7}$, Carlos Pérez-Plasencia ${ }^{2,3}$, Mariano Guardado-Estrada ${ }^{1}$

${ }^{1}$ Laboratorio de Genética de la Licenciatura en Ciencia Forense, Facultad de Medicina, Universidad Nacional Autónoma de México, Ciudad de México, México.

${ }^{2}$ Laboratorio de Genómica, Instituto Nacional de Cancerología, Ciudad de México, México.

${ }^{3}$ Laboratorio de Genómica, Unidad de Biomedicina, Facultad de Estudios Superiores Iztacala, Universidad Nacional Autónoma de México, Estado de México, México.

${ }^{4}$ Cátedras CONACYT - Ciencia Forense, Facultad de Medicina, Universidad Nacional Autónoma de México, Ciudad de México, México.

${ }^{5}$ Laboratorio Genómica del Cáncer, Instituto Nacional de Medicina Genómica, Ciudad de México, México.

${ }^{6}$ Laboratorio de Entomología de la Licenciatura en Ciencia Forense, Facultad de Medicina, Universidad Nacional Autónoma de México, Ciudad de México, México.

${ }^{7}$ Laboratorio de Toxicología de la Licenciatura en Ciencia Forense, Facultad de Medicina, Universidad Nacional Autónoma de México, Ciudad de México, México.

Corresponding Author:

Mariano Guardado-Estrada ${ }^{1}$

Circuito de la Investigación SN, Ciudad Universitaria, C.P. 04360. Ciudad de México, UNAM.

México. Email address: mguardado@cienciaforense.facmed.unam.mx 


\section{Abstract}

40

\section{(} 1

Background. The post-mortem interval (PMI) is the time elapsed since the dead of an individual until the body is found, which is relevant for forensic purposes. The miRNAs regulate the expression of some genes; and due to their small size, they can better support degradation, which makes them suitable for forensic analysis. In the present work, we evaluated the gene expression of miR-381-3p, miR-23b-3p, and miR-144-3p in skeletal muscle in a murine model at the early PMI.

Methods. We designed a rat model to evaluate the early PMI under controlled conditions. This model consisted in 25 rats divided into five groups of rats, that correspond to the $0,3,6,12$ and 24 hours of PMI. The 0 h-PMI was considered as the control group. Muscle samples were taken from each rat to analyze the expression of miR-381-3p, miR-23b-3p, and miR-144-3p by quantitative RT-PCR. The gene expression of each miRNA was expressed as Fold Change (FC) and compared among groups. To find the targets of these miRNAs and the pathways where they participate, we performed an in-silico analysis. From the gene targets of miR-381-3p identified in the silico analysis, the EPC1 gene was selected for gene expression analysis by quantitative RT-PCR in these samples. Also, to evaluate if miR-381-3p could predict the early PMI, a mixed effects model was calculated using its gene expression.

Results. An upregulation of miR-381-3p was found at 24 h-PMI compared with the control group of $0 \mathrm{~h}-\mathrm{PMI}$ and $(\mathrm{FC}=1.02$ vs. $\mathrm{FC}=1.96 ; \mathrm{p}=0.0079)$. This was the opposite for miR-23b$3 \mathrm{p}$, which had a down-regulation at $24 \mathrm{~h}-\mathrm{PMI}$ compared to $0 \mathrm{~h}-\mathrm{PMI}(\mathrm{FC}=1.22 \mathrm{vs} . \mathrm{FC}=0.13$; $\mathrm{p}=0.0079$ ). Moreover, the gene expression of miR-381-3p increased throughout the first $24 \mathrm{~h}$ of PMI, while it was the opposite for miR-23b-3p. The targets of these two miRNAs, participate in biological pathways related to hypoxia, apoptosis, and RNA metabolism. The gene expression of EPC1 was found downregulated at 3 and $12 \mathrm{~h}$ of PMI, whereas it remained unchanged at $6 \mathrm{~h}$ and $24 \mathrm{~h}$ of PMI. Using a multivariate analysis, it was possible to predict the FC of miR-381-3p of all but 6 h-PMI analyzed PMIs.

Discussion. The present results suggest that miR-23b-3p and miR-381-3p participate at the early PMI, probably regulating the expression of some genes related to the autolysis process as EPC1 gene. Although the miR-381-3p gene expression is a potential estimator of PMI, further studies will be required to obtain better estimates

2




\section{Introduction}

79 The post-mortem interval (PMI) is defined as the time elapsed between the dead of an individual 80 and the time the body is found; it being relevant for forensic purposes (Maile et al., 2017). At 81 early PMI (3 to $72 \mathrm{~h}$ after death), morphological changes appear, such as decay of temperature 82 (algor mortis), cadaveric stiffness (rigors mortis), and changes in body coloration (livor mortis) 83 (Lee Goff, 2009; Maile et al., 2017). The identification of these morphological changes is helpful 84 to estimate the PMI. In the meantime, a process called autolysis occurs in the cells of a dead 85 body, characterized by an absence of inflammatory response and cell destruction due to 86 liberation of the enzymes of some organelles (Tomita et al., 2004).

87 However, the occurrence of these external morphological changes could vary due to different 88 factors such as the environment, cause of the death, among others; this can make it difficult to 89 estimate PMI (Madea, 2016). Thus, other methods have been developed where some components 90 in vitreous humor or synovial fluid are quantified for PMI estimation (Madea et al., 1994; 91 Madea, Kreuser \& Banaschak, 2001; Zilg et al., 2015; Madea, 2016; Ansari \& Menon, 2017).

92 Nevertheless, as with physical changes, variations in the quantifications of these elements reduce 93 the confidence in the calculation of PMI (Muñoz Barús et al., 2002; Madea, 2016).

94 Other molecules that have been studied for PMI estimation are nucleic acids (Koppelkamm et al., 95 2011; Itani et al., 2011). For instance, RNA degradation has been studied in different tissues 96 throughout the PMIs (Koppelkamm et al., 2011). Although it is expected that after the death of 97 an individual the RNA transcription halts, there are many studies that analyze the expression of 98 some genes at different PMIs (Pozhitkov et al., 2017). After death, transcriptional activity has 99 been found in several tissues analyzed in humans and other organisms (Vishnoi \& Rani, 2017; 100 Pozhitkov et al., 2017; Ferreira et al., 2018). For instance, a study performed in mice and zebra fish found an upregulation of genes that participate in several biological processes such as stress, immune response and apoptosis, among others (Pozhitkov et al., 2017). In humans, the changes of transcriptional activity at early PMI depend on the analyzed tissue, as well as the rate of RNA degradation in them (Ferreira et al., 2018). Although there is no complete understanding of the underlying mechanism of this transcriptional activity at PMI, it is suggested that epigenetic regulation could be involved (Pozhitkov et al., 2017).

108

109 The miRNAs are small 22 nucleotide-length non-coding RNAs which can post-transcriptionally regulate the expression of genes implicated in several pathways (Vishnoi \& Rani, 2017). Due to their small size, the miRNAs endure extreme conditions without degradation, making them suitable for forensic purposes (Wang et al., 2013; Lv et al., 2014). In fact, it has been reported that miRNAs regulate several processes such as apoptosis and inflammation, which are implicated in the process of body decomposing (Chen et al., 2018b; Zhou et al., 2019; Jiang et al., 2020). On the other hand, a continuous expression of some miRNAs at different PMI has 114 been found in the spleen, heart muscle, brain, and bone on both rats and humans (Li et al., 2014; 115 Lv et al., 2014; Nagy et al., 2015; Na, 2020). 
117 For this work we analyzed the expression of miR-144-3p, miR-23b-3p, and miR-381-3p, which 118 participate in apoptosis and inflammation, in rat skeletal muscle at early PMI. In fact, it has been 119 reported that miR-144-3p, miR-23b-3p and miR-381-3p regulates the gene expression of BCL6, 120 PROK2, and IL15RA, respectively, which were found to be altered at the PMI (Pozhitkov et al., 121 2017; Kozomara, Birgaoanu \& Griffiths-Jones, 2019). First, we established a PMI rat model to 122 analyze the expression of these three miRNAs in rat skeletal muscle at different post-mortem

123

124

125

126

127

128

129

130

131

132

133

134

135

136

137

138

139

140

141

142

143

144

145

146

147

148

149

150

151

152

153

154

155

156 intervals. On the other hand, we performed an in-silico analysis to identify the gene targets of these miRNAs to quantify one of them in these samples. Finally, the expression of EPC1, which is target of miR-381-3p in these samples, was analyzed.

\section{Materials \& Methods}

PMI rat model.

A total of 25 adult male Wistar rats was selected for the study; all with an average weight of 200 $+/-20$ gr. These rats were sorted into five groups, which correspond to the $0,3,6,12$ and 24 hours of post-mortem interval (h-PMI). The $0 \mathrm{~h}$-PMI was considered the control group. The rats from 3, 6, 12 and 24 h-PMI groups, were euthanized by cervical dislocation and placed in a Binder KBW $240^{\mathrm{TM}}$ climatic chamber with a constant temperature of $25^{\circ} \mathrm{C}$. After the PMI time elapsed in each group, the presence of internal and external morphological changes was evaluated on every rat. Every rat was physically explored, in a cephalocaudal fashion, to evaluate the presence or absence of algor mortis (AM), livor mortis (LM), rigor mortis upper body (RMU), rigor mortis lower body (RML), drying (DR), generalized edema (ED), hair loss (HL), abdomen green discoloration (AGD), and abdominal distention (AD), which are physical signs present at early post-mortem interval (Dix, 1999; Brooks, 2016). Also, each animal was dissected to evaluate the presence of brain liquefaction (BL), brain edema (BE), discoloration of liver (DL), loss of liver consistency (LLC), muscle livor mortis (MML), bowel swelling (BS), ascites (AS), and loss of muscle consistency (LMC). Once the evaluation was performed, 200 mg of femoral muscle sample was obtained and stored at $-80^{\circ} \mathrm{C}$ until analysis. The rats from the control group were euthanized by cervical dislocation, and muscle samples were taken immediately and stored at $-80^{\circ} \mathrm{C}$ until analysis. As in the other PMI-groups, control group rats were externally and physically evaluated for the presence of cadaveric signs. All procedures were evaluated and approved by the local ethic and scientific committee and the committee for the care and use of laboratory animals (CICUAL) of the Faculty of Medicine from the National Autonomous University of Mexico (UNAM) with approval number 102-2018, and with approval number 027-CIC-201, respectively; the procedures were also performed in strict accordance to local (NOM-062-ZOO-1999) and international norms of laboratory animals handling.

RNA extraction.

For miRNAs analysis, total RNA was extracted from the rat skeletal muscle samples using glass beads for rupture and Trizol ${ }^{\mathrm{TM}}$ Reagent. In brief, a fraction between 50 and $100 \mathrm{mg}$ of frozen 
157 tissue was collected in a $2 \mathrm{~mL}$ tube with $2 \mathrm{~mm}$ glass beads (ZR BashingBead Lysis Tubes, Zymo

158

159

160

161

162

163

164

165

166

167

168

169

170

171

172

173

174

175

176

177

178

179

180

181

182

183

184

185

186

187

188

189

190

191

192

193

194

195

Research) and $1 \mathrm{~mL}$ of Trizol ${ }^{\mathrm{TM}}$ Reagent. Then, $200 \mu \mathrm{l}$ of clorophorm was added and mixed to be centrifuged at $12,000 \mathrm{~g}$ for $15 \mathrm{~min}$ at $4^{\circ} \mathrm{C}$. After this step, total RNA extraction was performed according to manufacturer's recommendations. The obtained RNA was quantified with an UV- spectrophotomer NanoDrop ${ }^{\mathrm{TM}} 2000$ (Thermo Scientific), and the integrity was evaluated qualitatively in agarose gels.

miRNAs quantification by RT-PCR.

From the total RNA of muscle samples, miRNA cDNA was synthetized using the kit TaqMan Advanced miRNA cDNA Synthesis kit (Applied Biosystems). This kit performs the poly(A) tailing reaction via adaptor ligation previous to the miRNA cDNA synthesis. All reactions were performed according to the manufacturer's protocol. Gene expression of miR-144-3p, miR-23b$3 p$, and miR-381-3p was evaluated by qRT-PCR using the TaqMan ${ }^{\circledR}$ probes rno481325_mir, rno478602_mir, and rno481460_mir, respectively. The miR-361-5p (rno481127_mir) was used as internal control, since it has been seen that its expression is stable under extreme conditions, such as cancer (Della Bella \& Stoddart, 2019). The miRNas quantification was performed in a StepOne ${ }^{\mathrm{TM}} \square$ Real-Time PCR System (Thermo Fisher Scientific, Waltham, Massachusetts, U.S.A) using $10 \mathrm{ng}$ of total cDNA, $0.5 \mu$ of the TaqMan ${ }^{\circledR}$ Advanced miRNA Assay (20X), and $5 \mu \mathrm{l}$ of TaqMan ${ }^{\circledR}$ Fast Advanced Master Mix (2X) in a total volume of $7.5 \mu$ l. Each quantitative RT-PCR was incubated at $95^{\circ} \mathrm{C}$ for $20 \mathrm{~s}$, then at $95^{\circ} \mathrm{C}$ for 3 min with 40 cycles of denaturation and annealing/extension at $60^{\circ} \mathrm{C}$ for $30 \mathrm{~s}$. Each miRNA was analyzed separately, and each sample was run by triplicate. Each miRNA was relatively quantified with the $2^{-\Delta \Delta \mathrm{CT}}$ method, and data is presented as fold change (FC), which is the gene expression normalized to miR-361-5p and relative to the 0 h-PMI group (Livak \& Schmittgen, 2001).

mRNA quantification by RT-PCR.

From the total RNA extracted from the rat's muscle samples, cDNA was synthetized using HighCapacity cDNA Reverse Transcription Kit (Thermo Fisher Scientific, Waltham, Massachusetts, U.S.A). The reaction was performed in a total volume of $20 \mu$, which included $1 \mathrm{mg}$ of RNA, 2 $\mu 1$ of 10X RT Buffer, $0.8 \mu 1$ of 25X dNTP Mix, $2 \mu 1$ of 10X RT Random Primers, and $1 \mu 1$ of MultiScribe Reverse Transcriptase. Reactions were incubated at $25^{\circ} \mathrm{C}$ for 10 minutes, at $37^{\circ} \mathrm{C}$ for 120 minutes, and at $85^{\circ} \mathrm{C}$ for 5 minutes; then they were stored at $-20^{\circ} \mathrm{C}$ for further analyses. Gene expression of $E P C l\left(\mathrm{Rn} 01538512 \_\mathrm{m} 1\right)$ was evaluated with RT-PCR using TaqMan $\mathbb{}$ probes. To normalize the expression of EPC1, the ACTB gene (Rn00667869_m1) was used in the analysis as a housekeeping gene. Quantification was performed in a StepOne ${ }^{\mathrm{TM}} \square$ Real-Time PCR System (Thermo Fisher Scientific, Waltham, Massachusetts, U.S.A) using $45 \mathrm{ng}$ of total cDNA, $1 \mu 1$ of the Taqman ${ }^{\mathrm{TM}} \square$ Probe, and $10 \mu \mathrm{l}$ of Taqman ${ }^{\circledR}$ Master Mix in a total volume of 20 $\mu 1$. Each quantitative RT-PCR was incubated at $50^{\circ} \mathrm{C}$ for $2 \mathrm{~min}$, then at $95^{\circ} \mathrm{C}$ for $10 \mathrm{~min}$ with 40 cycles of denaturation at $90^{\circ} \mathrm{C}$, and annealing/extension at $60^{\circ} \mathrm{C}$ for $60 \mathrm{~s}$. Each gene was

PeerJ reviewing PDF | (2020:08:51757:1:1:NEW 10 Feb 2021) 
196

197

198

199

200

201

202

203

204

205

206

207

208

209

210

211

212

213

214

215

216

217

218

219

220

221

222

223

224

225

226

227

228

229

230

231

232

233

234

235

analyzed separately and ran by triplicate in all samples. The average CT threshold calculated for each sample was used to relatively quantify the EPCl gene expression using the $2^{-\triangle \Delta C T}$ method expressed as Fold-Change (FC). (Livak \& Schmittgen, 2001).

\section{The miRNAs target identification analysis and their pathways.}

The gene targets of the miRNAs miR-23b-3p, and miR381-3p were identified in silico using several bioinformatic databases, that included predicted and experimentally validated targets. For predicted targets, the databases DIANA-microT-CDS (Reczko et al., 2012; Paraskevopoulou et al., 2013), ElMMo (http://www.mirz.unibas.ch/ElMMo/), MicroCosm

(https://omictools.com/microcosm-targets-tool), miRanda (http://www.microrna.org/microrna/getDownloads.do), miRDB (http://mirdb.org/), PicTar (https://pictar.mdc-berlin.de/), PITA (Segal Lab of Computational Biology, https://genie.weizmann.ac.il/pubs/mir07/mir07_prediction.html), and TargetScanHuman (http://www.targetscan.org/vert_72/) were used. Additionally, the validated targets were searched in the miRecords (http://c1.accurascience.com/miRecords/), miRTarBase (Chou et al., 2018), and TarBase (Karagkouni et al., 2018). For each miRNA, we selected only those target genes which were present in at least three or more databases (Script in Supplemental Data). Moreover, to identify the biological pathways where these gene targets participate, we analyzed them further with the Gene Set Enrichment Analysis (GSEA) from WEB-based Gene Set Analysis Toolkit (WebGestalt, http://www.webgestalt.org/). Only those biological pathways with a False Discovery Rate (FDR) less than 0.05 were considered.

\section{Statistical analysis.}

The presence or absence of morphological changes through the PMI in rats was evaluated with the Multiple Correspondence Analysis. The FC of each miRNA was compared among the PMIs with the non-parametric Kruskal Wallis and the Mann U Whitney test. Using the Cohen's d calculation and expecting a large effect size $(\mathrm{d}=0.8)$, we expected a statistical power of 0.8 with the sample size of each group in the present study (Lakens, 2013). The dependence and association of the morphological changes with the PMI were evaluated with the Pearson's Chisquared test and Cochran-Armitage test, respectively. To explore whether there is an association between the post-mortem interval and the expression of miR-381-3p and miR-23b-3p a Spearman Rho correlation was calculated. A Mixed Effect Model was calculated considering the FC, the morphological changes of brain liquefaction and cerebral edema with PMI, as an independent variable $(\mathrm{y}=\mathrm{X} \beta+\mathrm{Z} \gamma+\varepsilon$; where: $\mathrm{y}$ is the response vector of all the observations; $\mathrm{X}$ is a fixed effects design matrix; $\beta$ is a $p$ fixed effects vector; $Z$ is a random effects design matrix; $\gamma$ is a random effects vector; and $\varepsilon$ is the observation error vector) in the "ImerTest" package with the active option of the REML (Restricted Maximum Likelihood). All statistics were performed with the R-project software (https://www.r-project.org/). The dataset and scripts can be found in github (https://github.com/nshuerta-ForenseUNAM/Dysregulation miRNA).

\section{Results}


236 Morphological changes are heterogenous at different post-mortem intervals in rats.

237 Internal and external physical changes were evaluated at different post-mortem intervals in 25 238 rats. The external physical changes evaluated included algor mortis (AM), livor mortis (LM), 239 rigor mortis upper body (RMU), rigor mortis lower body (RML), drying (DR), generalized 240 edema (ED), hair loss (HL), abdomen green discoloration (AGD) and abdominal distention 241 (AD). All but RML, ED and AGD, appeared after the first 3 hours of PMI (see Table 1). On the 242 other hand, the AGD was not observed until the $12 \mathrm{~h}$ of PMI. In the case of rigor mortis, the 243 RMU and the RML was only seen from 3 to $6 \mathrm{~h}-\mathrm{PMI}$ and 6 to $12 \mathrm{~h}$-PMI, respectively.

244 All animals were dissected to evaluate the following macroscopic characteristics: brain 245 liquefaction (BL), brain edema (BE), discoloration of liver (DL), loss of liver consistency (LLC), 246 muscle livor mortis (MML), bowel swelling (BS), ascites (AS), and loss of muscle consistency 247 (LMC). As in the external characteristics, all these changes but for AS and LMC were gradually

248

249

250

251

252

253

254

255

256

257

258

259

260

261

262

263

264

265

266

267

268

269

270

271

272

273

274

275 seen after $3 \mathrm{~h}$ of PMI. Interestingly, AS and LMC did not appear until $24 \mathrm{~h}-\mathrm{PMI}$ and were present in 60 and $80 \%$ of the analyzed animals, respectively.

These morphological changes were evaluated in a Multiple Correspondence Analysis (MCA) in order to see how these characteristics group through the PMI (See Figure 1a). The MCA plot captured at least the $74.2 \%$ of the data and, as it was expected, the morphological characteristics of the $0 \mathrm{~h}$-PMI and the $24 \mathrm{~h}$-PMI were located opposite from each other. Also, there were PMIs that clustered into three groups because they shared some morphological characteristics among them (See Figure 1b). The first group included 0 and 3 h-PMI, the second the 6 and 12 h-PMI, and the third the $24 \mathrm{~h}$-PMI. Group I is consistent with the few morphological changes present within the first 3 hours of PMI, while group III is where all the early PMI physical characteristics have been established. However, in group II, there were characteristics that were present or absent in both, the 6 and 12 h-PMI, which did not allow to differentiate them in the MCA. These data suggest that the estimate of PMI using morphological changes could be more precise between 0 to $3 \mathrm{~h}-\mathrm{PMI}$ and at $24 \mathrm{~h}-\mathrm{PMI}$ of death.

miR-381-3p and miR-23b-3p showed gene expression imbalances throughout different PMIs in rats.

The gene expression of miR-381-3p, miR-23b-3p, and miR-144-3p was analyzed using qRTPCR in skeletal muscle of rats exposed to the PMIs aforementioned (see material and methods). Interestingly, miR-381-3p was found upregulated at the $24 \mathrm{~h}-\mathrm{PMI}$ group of rats compared to the 0 h-PMI control $(F C=1.02$ vs. $F C=1.96 ; p=0.0079$, Mann $U$ Whitney test; Figure $2 a)$. When the FC of miR-381-3p was analyzed at different PMIs, the gene expression of this miRNA had a Jshape curve (see Figure 2a). First, within the three hours of PMI, the expression of miR-381-3p was downregulated $(\mathrm{FC}=0.73)$, compared to controls, and this difference was statistically significant ( $\mathrm{p}=0.0317$, Mann $\mathrm{U}$ Whitney test; Figure 2a). In fact, the difference in the miR-381$3 p$ gene expression was more evident when comparing the $3 \mathrm{hr}-\mathrm{PMI}$ with the $24 \mathrm{~h}-\mathrm{PMI}$ $(p=0.0079$, Mann U Whitney test). Nevertheless, after the $3 \mathrm{~h}-\mathrm{PMI}$, the expression of this miRNA gradually increased from 6 hours of PMI to 24 hours of PMI interval (see Figure 2a). As

Peer) reviewing PDF | (2020:08:51757:1:1:NEW 10 Feb 2021) 
276 it was expected, the difference in the gene expression between $3 \mathrm{~h}$-PMI and $12 \mathrm{~h}$-PMI was

277 statistically significant ( $\mathrm{p}=0.032$, Mann U Whitney test).

278 Contrary to miR-381-3p, the gene expression of miR-23b-3p decreased as the PMI increases to

27924 hours. The gene expression of miR-23b-3p was downregulated at $24 \mathrm{~h}$-PMI compared to $0 \mathrm{~h}-$ 280 PMI, and this difference was statistically significant $(\mathrm{FC}=1.22$ vs. $\mathrm{FC}=0.13 ; \mathrm{p}=0.0079$, Mann $\mathrm{U}$ 281 Whitney test; Figure 2b). Interestingly, when the FC of miR-23b-3p was analyzed by the PMIs, 282 the expression of this miRNA decreased from the $3 \mathrm{~h}$-PMI to the $24 \mathrm{~h}$-PMI (see Figure $2 \mathrm{~b}$ ).

283 There were significant differences comparing 3 h-PMI vs 24 h-PMI ( $\mathrm{p}=0.0079$, Mann U Whitney 284 test), 6 h-PMI vs. 24 h-PMI ( $\mathrm{p}=0.0079$, Mann U Whitney test) and $12 \mathrm{~h}$-PMI vs. 24 h-PMI $285(\mathrm{p}=0.0079$, Mann U Whitney test).

286 Finally, although the FC of miR-114-3p decreased from 0 h-PMI to 6 h-PMI, these differences 287 were not significant ( $>0.05$, Mann U Whitney test; see Figure $2 \mathrm{c}$ ). In fact, the FC remained 288 unchanged in the following two post-mortem intervals. These results suggest that there is a 289 dysregulation in gene expression of miR-381-3p and miR-23b-3p as the time of post-mortem 290 interval increases in rats.

291

292 Biological process related to miR-381-3p and miR-23b-3p.

293 Using different miRNAs bioinformatic databases (see material and methods), we identified the 294 target genes of miR-381-3p and miR-23b-3p. A total of 2122 and 2076 genes were found to be 295 regulated by miR-381-3p and miR-23b-3p, respectively (Supplemental Table 1). With each set of 296 genes, a Gene Ontology enrichment analysis was performed to find the main biological processes 297 where they participate (see material and methods). In the case of miR-381-3p, a total of ten 298 biological processes were found to be regulated by this miRNA (see Figure 3a). Interestingly, 299 some of these biological processes are related to RNA processing as transcription, synthesis and 300 metabolism. Other processes involved with this miRNA, are the positive regulations of gene 301 expression.

302 On the other hand, a total of nine biological processes were associated with miR-23b-3p, which 303 were different compared with the target genes of miR-381-3p (see Figure $3 b$ ). For instance, the 304 two most enriched biological processes were those related to hypoxia response and oxygen 305 levels. On the other hand, there were processes related to the development of the central nervous 306 system. Interestingly, other complex cellular pathways were implicated with this miRNA as 307 positive regulation of signaling, phosphorylation and cell location. Although none of the 308 biological processes where this miRNA participated are related to apoptosis and inflammation, it 309 seems that their function in PMI would be related to the decomposing process of the body.

310

311 Gene expression analysis of EPC1.

312 From the target gene list that is regulated by miR-381-3p, EPCl was selected for gene

313 expression analyses with qRT-PCR in the same samples used for miRNAs analyses. Despite not 314 seeing a trend as with miR-381-3p, there was a downregulation of EPC1 gene expression at $3 \mathrm{~h}-$ 315 PMI ( $F C=1.04$ vs. $F C=0.58 ; \mathrm{p}=0.05$, Mann $\mathrm{U}$ Whitney test $)$ and $12 \mathrm{~h}-\mathrm{PMI}(\mathrm{FC}=1.04$ vs. $\mathrm{FC}=$ 
$3160.57 ; \mathrm{p}=0.01$, Mann U Whitney test) compared to the control group of $0 \mathrm{~h}-\mathrm{PMI}$. These

317 differences were statistically significant (see Figure 4). Also, there was a slight increase in the

318 expression of $E P C 1$ gene at $6 \mathrm{~h}-\mathrm{PMI}$ and at $24 \mathrm{~h}$-PMI compared to $0 \mathrm{~h}-\mathrm{PMI}$, though this was not

319 significant. These results indicate that $E P C l$ is down regulated or has no change in its expression

320 at different post-mortem intervals.

321

322

323

324

325

326

327

328

329

330

331

332

333

334

335

336

337

338

339

340

341

342

343

344

345

346

347

348

349

350

351

352

353

354

Estimation of PMI analyzing gene expression of miR-381-3p.

A Spearman Rho correlation was calculated with the FC of miR-381-3p from $3 \mathrm{~h}-\mathrm{PMI}$ to $24 \mathrm{~h}$ PMI, showing a value of $r=1(p=0.037)$. Since a descriptive pattern and association were observed in some variables, we considered that a model could give certainty that effects (fixed or random) affect the fold change of miR-381-3p. To evaluate this, a mixed effect model was calculated considering the FC (dependent variable), the morphological changes, and PMI as independent variables (see material and methods). From the morphological changes analyzed, only the presence of brain liquefaction and brain edema were significantly associated with the FC $(p<0.01)$. An approach to estimate the FC according to PMI of miR-381-3p was done with this model. First, the FC values with respect to change of time (PMI) and the presence or absence of brain liquefaction and brain edema were estimated. Through this model, it is possible to indirectly calculate the PMI, comparing the real FC, with the calculated confidence interval of the estimated FC. The mean FC estimated for $0 \mathrm{~h}$-PMI was $1.01 \pm 0$ (95\% CI, 1.01-1.01), 3 h-PMI to $0.73 \pm 0.04$ (95\% CI, 0.690.77), 6 h-PMI to $1.26 \pm 0.64$ (95\% CI, 0.62-1.90), 12 h-PMI to $1.47 \pm 0$ (95\% CI, 1.47- 1.47), and 24 h-PMI to $1.96 \pm 0$ (95\% CI, 1.96-1.96), respectively. It is important that there be no variability in the PMIs of 0,12 and $24 \mathrm{~h}$, in the estimated values for the FC, so the value in both limits is the same as the mean. According to our results, although the FC of miR-381-3p could be a good predictor of the $0,3,12$ and $24 \mathrm{~h}$-PMI, the high variability observed at 6 h-PMI hinders the estimation of an accurate interval of PMI according to FC. Albeit he Spearman Rho correlation was negatively significant to the FC of miR-23b-3p according to PMI $(r=-0.9, p<0.05)$, there was no significance in the PMI and morphological variables when the mixed effects model was calculated (data not shown).

\section{Discussion}

In the present work we found a gene expression dysregulation of miRNAs miR-381-3p and miR$23 \mathrm{~b}-3 \mathrm{p}$ in skeletal muscle tissue of rats exposed to different post-mortem intervals compared to the control group. The miR-23b-3p gene expression decreased from 3 to $24 \mathrm{~h}$ of PMI. On the contrary, the gene expression of miR-381-3p increased, with a J-shape curve, as the PMI increased. These two miRNAs regulate the expression of genes which participate in different processes as hypoxia or oxygen depletion sensing, and RNA transcription. Moreover, the gene expression of $E P C 1$, which is a gene target of miR-381-3p, was found downregulated or with no change at early PMI, compared to the 0 -PMI. Using a mixed effect model, the Fold-change of miR-381-3p could be predicted at $0,3,12$ and $24 \mathrm{~h}$ of PMI.

PeerJ reviewing PDF | (2020:08:51757:1:1:NEW 10 Feb 2021) 
355

356

357

358

359

360

361

362

363

364

365

366

367

368

369

370

371

372

373

374

375

376

377

378

379

380

381

382

383

384

385

386

387

388

389

390

391

392

393

394

The presence of several miRNAs in various tissues has been described through the PMI in humans and in rats (Lv et al., 2017; Tu et al., 2019). However, the analyzed gene expression of some miRNAs has been mainly focused in finding control genes potentially useful for PMI calculation based on gene expression analysis in death bodies. For instance, the gene expression of miR-9 and miR-125b barely fluctuates throughout the different PMI analyzed in spleen (Lv et al., 2014). Nevertheless, within the first $24 \mathrm{~h}$ of PMI, an upregulation or downregulation of some miRNAs has also been found ( $\mathrm{Lv}$ et al., 2014). In the rat's brain, a slight downregulation of miR16 was found throughout the $24 \mathrm{~h}$ of PMI (Nagy et al., 2015). On the contrary, miR-124a, miR205 , and miR-21 were found upregulated within the first $24 \mathrm{~h}$ of PMI in brain and skin (Nagy et al., 2015; Ibrahim et al., 2019). These studies and our results suggest that some miRNAs could be actively involved in the decomposing process, possibly regulating the expression of other genes, rather than being inert molecules which heavily resist degradation.

After the death of an individual, the autolysis process is seen as a necessary step to achieve body decomposition, and it occurs nearly immediately after the death of the individual (C. Zapico, Menéndez \& Núñez, 2014). Nevertheless, more than the liberation of enzymes and proteasomal degradation, the autolysis process is a complex process, where a struggle between survival and pro-apoptotical signals takes place (Sanoudou et al., 2004). On the other hand, it has been reported that several genes, some of them related to cell survival, are dysregulated in the PMI that could last for several days (Sanoudou et al., 2004; Zhu et al., 2017; Ferreira et al., 2018). Thus, it is possible that those genes transcriptionally active favor the body decomposition activating pathways such as apoptosis (C. Zapico, Menéndez \& Núñez, 2014). This can also be seen in the biological pathways where the gene targets of the altered miRNAs found in our study participate. Each miRNA regulates different processes that could be related to the autolysis process such as RNA transcription or oxygen levels sensing.

In humans, the miR-381 has been considered as a tumor suppressor in prostate and non-small cell lung cancer inhibiting cell proliferation, invasion and migration through inhibition of nuclear factor-kB signaling (Formosa et al., 2014; Huang et al., 2018). Regarding the PMI, the increase of this miRNA expression could be as a mechanism for promoting apoptosis related to oxidative stress produced by the hypoxia. Another mechanism where miR-381 could participate in PMI is the inflammation inhibition in the autolysis process (Chen et al., 2018a). Interestingly, we found a downregulation of EPC1 gene at $3 \mathrm{~h}-\mathrm{PMI}$ and $12 \mathrm{~h}$-PMI compared to the control group of 0PMI, and no change at 6 and 24 of PMI. The enhancer of polycomb homolog 1 (EPC1) gene codes for a protein member of the polycomb group (PcG) family and is gene target of miR-381 (Kozomara, Birgaoanu \& Griffiths-Jones, 2019). The coded product of EPCl is a part of the NuA4 (Nucleosome Acetyltransferase of H)/TIP60 (Tat Interacting Protein 60) acetyltransferase complex, which participate in several processes to repair DNA double strand breaks (DBSs) and apoptosis (Zhang et al., 2020). Also, it has been reported that $E P C l$ acts as an oncogene in some types of cancer, such as acute myeloid leukemia (AML), since its suppression triggered 
395

396

397

398

399

400

401

402

403

404

405

406

407

408

409

410

411

412

413

414

415

416

417

418

419

420

421

422

423

424

425

426

427

428

429

430

431

432

433

434

apoptosis in cell lines (Huang et al., 2014). Our results suggest that one of the mechanisms in miR-381 that may promote apoptosis could be by down-regulation of $E P C 1$, although these results should be confirmed in further works to undermine these mechanisms in the PMI.

Contrary to miR-381, the miR-23b-3p showed a gradual reduction of its expression throughout the analyzed PMIs. The miR-23b-3p has been considered as an onco-miR in several types of cancers, such as gastric or breast cancer (Chen et al., 2012; Hu et al., 2017). Also, it has been found in osteosarcoma that miR-23b-3p promotes cell proliferation, while inhibiting oxidative phosphorylation increasing the lactate levels in these cells (Zhu, Li \& Ma, 2019). Nonetheless, it is important to emphasize that these results were found in cancer, which could differ from PMI, where the metabolism of the cell is strictly anaerobic (Donaldson \& Lamont, 2015). The proliferation mediated by miR-23b-3p is due to activation of TGF- $\beta$ signaling by inhibition of TGIF1 (Barbollat-Boutrand et al., 2017). Also, miR-23b-3p regulates many genes which participate in processes related to oxygen consumption. The participation of this miRNA in the PMI could be in the regulation of the expression of genes related to the response of lower levels of oxygen, which is expected due to the oxygen deprivation in the dead body. For instance, it has been found in mice, that in the first $24 \mathrm{~h}$ of PMI, there is an upregulation of hypoxia-related gene transcripts as Degs2 (Pozhitkov et al., 2017). Although we could not discard that the downregulation found on miR-23b-3p at the PMI is due to a higher degradation rate compared to other miRNAs at PMI, its function seems to be closely related with oxygen deprivation present at PMI.

Several works have used the $\mathrm{C}_{\mathrm{T}}$ obtained from some genes to estimate the PMI through univariate or multivariate linear regression analyses with high coefficient of determination ( $\mathrm{Li}$ et al., 2014; Lv et al., 2014; Tu et al., 2019). In our study we used the FC, which relatively estimates the change in expression compared to a control group. From the three miRNAs that we analyzed, the only significant model to estimate the FC was miR-381-3p with a good coefficient of determination $\left(\mathrm{r}^{2}=0.91\right)$. Except for the $6 \mathrm{~h}$-PMI, we were able to estimate the FC according to the 3,12 and $24 \mathrm{~h}$ of PMI. This could be due to a high variability of miR-381-3p expression found at $6 \mathrm{~h}$-PMI, that may be related to individual differences in the autolysis process at this PMI. Interestingly, this variability was also seen in the physical characteristics of the rats at this PMI, which was corroborated in the Multiple Correspondence Analysis. One explanation of this variability is that, at this PMI, there is a heterogeneity in rat's body decomposition; thus, we found rats that presented morphological changes above or below the $6 \mathrm{~h}$ mark.

Although we found differences in the gene expression of miR-381-3p and miR-23b-3p in rat skeletal muscle throughout the post-mortem interval, it is important to mention the limitations of the present study. For instance, the sample size from each group in the present study is limited and the findings should be taken as exploratory. Also, it is possible that the analyzed PMIs could not fully reflect the main biological processes occurring in the early post-mortem interval, so 
435 further studies involving more PMIs would be required to better define these processes. Since the 436 PMI is a complex biological process, it is probable that there are other miRNAs interacting with 437 other genes in this process. Finally, the conditions of the experiments were performed in an 438 animal model by controlling the environmental conditions, such as temperature and humidity, 439 which can differ drastically from real forensic scenarios. For this reason, we cannot discard that 440 the expression of these miRNAs could vary across different environmental conditions.

441

442

443

444

445

446

447

448

449

450

451

452

453

454

455

456

457

458

459

460

461

462

463

464

465

466

467

468

469

470

471

472

473

474

475

476

477

\section{Conclusions}

The gene expression dysregulation of $\mathrm{miR}-381-3 \mathrm{p}$ and $\mathrm{miR}-23 \mathrm{~b}-3 \mathrm{p}$ found in rat muscle at early post-mortem intervals, suggest that these miRNAs participate in the autolysis process. The targets of these miRNAs are involved in pathways related to hypoxia, apoptosis and RNA metabolism. The EPC1 gene target of miR-381-3p was found downregulated or with no change at an early post-mortem interval. Although miR-381-3p gene expression could be a promising biomarker for post-mortem interval estimation, further studies will be required to refine these predictions.

\section{Acknowledgements}

This work was supported by the National Autonomous University of Mexico (UNAM), PAPIIT grant number IA204420. This study was part of the dissertation to obtain the Ms C. degree of Vanessa Martínez Rivera at the Posgrado de Maestría en Ciencias Biológicas, Universidad Nacional Autónoma de México (UNAM).

\section{References}

Ansari N, Menon SK. 2017. Determination of Time since Death using Vitreous Humor Tryptophan. Journal of Forensic Sciences 62:1351-1356. DOI: 10.1111/1556-4029.13430.

Barbollat-Boutrand L, Joly-Tonetti N, Dos Santos M, Metral E, Boher A, Masse I, BerthierVergnes O, Bertolino P, Damour O, Lamartine J. 2017. MicroRNA-23b-3p regulates human keratinocyte differentiation through repression of TGIF1 and activation of the TGF- $\beta$ SMAD2 signalling pathway. Experimental Dermatology 26:51-57. DOI:

10.1111/exd.13119.

Della Bella E, Stoddart MJ. 2019. Cell detachment rapidly induces changes in noncoding RNA expression in human mesenchymal stromal cells. BioTechniques 67:286-293. DOI: 10.2144/btn-2019-0038.

Brooks JW. 2016. Postmortem Changes in Animal Carcasses and Estimation of the Postmortem Interval. Veterinary Pathology 53:929-940. DOI: 10.1177/0300985816629720.

C. Zapico S, Menéndez ST, Núñez P. 2014. Cell death proteins as markers of early postmortem interval. Cellular and Molecular Life Sciences 71:2957-2962. DOI: 10.1007/s00018-0131531-x.

Chen L, Han L, Zhang K, Shi Z, Zhang J, Zhang A, Wang Y, Song Y, Li Y, Jiang T, Pu P, Jiang C, Kang C. 2012. VHL regulates the effects of miR-23b on glioma survival and invasion via suppression of HIF-1 $\alpha / \mathrm{VEGF}$ and $\beta$-catenin/Tcf-4 signaling. Neuro-Oncology 14:1026-

Peer) reviewing PDF | (2020:08:51757:1:1:NEW 10 Feb 2021) 
478

479

480

481

482

483

484

485

486

487

488

489

490

491

492

493

494

495

496

497

498

499

500

501

502

503

504

505

506

507

508

509

510

511

512

513

514

515

516

517

518

519

520

521

522

523

1036. DOI: 10.1093/neuonc/nos 122.

Chen WC, Luo J, Cao XQ, Cheng XG, He DW. 2018a. Overexpression of miR-381-3p promotes the recovery of spinal cord injury. European Review for Medical and Pharmacological Sciences 22:5429-5437. DOI: 10.26355/eurrev_201809_15802.

Chen G, Ma Y, Jiang Z, Feng Y, Han Y, Tang Y, Zhang J, Ni H, Li X, Li N. 2018b. Lico A Causes ER Stress and Apoptosis via Up-Regulating miR-144-3p in Human Lung Cancer Cell Line H292. Frontiers in Pharmacology 9. DOI: 10.3389/fphar.2018.00837.

Chou C-H, Shrestha S, Yang C-D, Chang N-W, Lin Y-L, Liao K-W, Huang W-C, Sun T-H, Tu S-J, Lee W-H, Chiew M-Y, Tai C-S, Wei T-Y, Tsai T-R, Huang H-T, Wang C-Y, Wu H-Y, Ho S-Y, Chen P-R, Chuang C-H, Hsieh P-J, Wu Y-S, Chen W-L, Li M-J, Wu Y-C, Huang X-Y, Ng FL, Buddhakosai W, Huang P-C, Lan K-C, Huang C-Y, Weng S-L, Cheng Y-N, Liang C, Hsu W-L, Huang H-D. 2018. miRTarBase update 2018: a resource for experimentally validated microRNA-target interactions. Nucleic Acids Research 46:D296D302. DOI: 10.1093/nar/gkx1067.

Dix J. 1999. Time of Death, Decomposition and Identification. CRC Press. DOI: $10.4324 / 9780367806422$.

Donaldson AE, Lamont IL. 2015. Metabolomics of post-mortem blood: identifying potential markers of post-mortem interval. Metabolomics 11:237-245. DOI: 10.1007/s11306-0140691-5.

Ferreira PG, Muñoz-Aguirre M, Reverter F, Sá Godinho CP, Sousa A, Amadoz A, Sodaei R, Hidalgo MR, Pervouchine D, Carbonell-Caballero J, Nurtdinov R, Breschi A, Amador R, Oliveira P, Çubuk C, Curado J, Aguet F, Oliveira C, Dopazo J, Sammeth M, Ardlie KG, Guigó R. 2018. The effects of death and post-mortem cold ischemia on human tissue transcriptomes. Nature Communications 9:490. DOI: 10.1038/s41467-017-02772-x.

Formosa A, Markert EK, Lena AM, Italiano D, Finazzi-Agro' E, Levine AJ, Bernardini S, Garabadgiu A V., Melino G, Candi E. 2014. MicroRNAs, miR-154, miR-299-5p, miR376a, miR-376c, miR-377, miR-381, miR-487b, miR-485-3p, miR-495 and miR-654-3p, mapped to the $14 \mathrm{q} 32.31$ locus, regulate proliferation, apoptosis, migration and invasion in metastatic prostate cancer cells. Oncogene 33:5173-5182. DOI: 10.1038/onc.2013.451.

Hu X, Wang Y, Liang H, Fan Q, Zhu R, Cui J, Zhang W, Zen K, Zhang C-Y, Hou D, Zhou Z, Chen X. 2017. miR-23a/b promote tumor growth and suppress apoptosis by targeting PDCD4 in gastric cancer. Cell Death \& Disease 8:e3059-e3059. DOI:

10.1038/cddis.2017.447.

Huang X, Spencer GJ, Lynch JT, Ciceri F, Somerville TDD, Somervaille TCP. 2014. Enhancers of Polycomb EPC1 and EPC2 sustain the oncogenic potential of MLL leukemia stem cells. Leukemia 28:1081-1091. DOI: 10.1038/leu.2013.316.

Huang R, Zheng Y, Zhao J, Chun X. 2018. microRNA-381 suppresses the growth and increases cisplatin sensitivity in non-small cell lung cancer cells through inhibition of nuclear factorКB signaling. Biomedicine \& Pharmacotherapy 98:538-544. DOI: 10.1016/j.biopha.2017.12.092.

Ibrahim SF, Ali MM, Basyouni H, Rashed LA, Amer EAE, Abd El-Kareem D. 2019. Histological and miRNAs postmortem changes in incisional wound. Egyptian Journal of Forensic Sciences 9:37. DOI: 10.1186/s41935-019-0141-7.

Itani M, Yamamoto Y, Doi Y, Miyaishi S. 2011. Quantitative analysis of DNA degradation in the dead body. Acta medica Okayama 65:299-306. DOI: 10.18926/AMO/47011.

Jiang X, Yu M, Zhu T, Lou L, Chen X, Li Q, Wei D, Sun R. 2020. Kcnq1ot1/miR-381-3p/ETS2

Peer) reviewing PDF | (2020:08:51757:1:1:NEW 10 Feb 2021) 
524

525

526

527

528

529

530

531

532

533

534

535

536

537

538

539

540

541

542

543

544

545

546

547

548

549

550

551

552

553

554

555

556

557

558

559

560

561

562

563

564

565

566

567

568

569

Axis Regulates Inflammation in Mouse Models of Acute Respiratory Distress Syndrome. Molecular Therapy - Nucleic Acids 19:179-189. DOI: 10.1016/j.omtn.2019.10.036.

Karagkouni D, Paraskevopoulou MD, Chatzopoulos S, Vlachos IS, Tastsoglou S, Kanellos I, Papadimitriou D, Kavakiotis I, Maniou S, Skoufos G, Vergoulis T, Dalamagas T, Hatzigeorgiou AG. 2018. DIANA-TarBase v8: a decade-long collection of experimentally supported miRNA-gene interactions. Nucleic Acids Research 46:D239-D245. DOI: 10.1093/nar/gkx1141.

Koppelkamm A, Vennemann B, Lutz-Bonengel S, Fracasso T, Vennemann M. 2011. RNA integrity in post-mortem samples: influencing parameters and implications on RT-qPCR assays. International Journal of Legal Medicine 125:573-580. DOI: 10.1007/s00414-0110578-1.

Kozomara A, Birgaoanu M, Griffiths-Jones S. 2019. miRBase: from microRNA sequences to function. Nucleic Acids Research 47:D155-D162. DOI: 10.1093/nar/gky1141.

Lakens D. 2013. Calculating and reporting effect sizes to facilitate cumulative science: a practical primer for t-tests and ANOVAs. Frontiers in psychology 4:863. DOI: 10.3389/fpsyg.2013.00863.

Lee Goff M. 2009. Early post-mortem changes and stages of decomposition in exposed cadavers. Experimental and Applied Acarology 49:21-36. DOI: 10.1007/s10493-009-9284-9.

Li W-C, Ma K-J, Lv Y-H, Zhang P, Pan H, Zhang H, Wang H-J, Ma D, Chen L. 2014. Postmortem interval determination using 18S-rRNA and microRNA. Science \& Justice 54:307-310. DOI: 10.1016/j.scijus.2014.03.001.

Livak KJ, Schmittgen TD. 2001. Analysis of Relative Gene Expression Data Using Real-Time Quantitative PCR and the 2- $\Delta \Delta \mathrm{CT}$ Method. Methods 25:402-408. DOI:

10.1006/meth.2001.1262.

Lv Y-H, Ma J-L, Pan H, Zeng Y, Tao L, Zhang H, Li W-C, Ma K-J, Chen L. 2017. Estimation of the human postmortem interval using an established rat mathematical model and multiRNA markers. Forensic Science, Medicine, and Pathology 13:20-27. DOI: 10.1007/s12024-016-9827-4.

Lv Y, Ma K, Zhang H, He M, Zhang P, Shen Y, Jiang N, Ma D, Chen L. 2014. A Time Course Study Demonstrating mRNA, microRNA, 18S rRNA, and U6 snRNA Changes to Estimate PMI in Deceased Rat's Spleen. Journal of Forensic Sciences 59:1286-1294. DOI: 10.1111/1556-4029.12447.

Madea B. 2016. Methods for determining time of death. Forensic Science, Medicine, and Pathology 12:451-485. DOI: 10.1007/s12024-016-9776-y.

Madea B, Käferstein H, Hermann N, Sticht G. 1994. Hypoxanthine in vitreous humor and cerebrospinal fluid - a marker of postmortem interval and prolonged (vital) hypoxia? Remarks also on hypoxanthine in SIDS. Forensic Science International 65:19-31. DOI: 10.1016/0379-0738(94)90296-8.

Madea B, Kreuser C, Banaschak S. 2001. Postmortem biochemical examination of synovial fluid - a preliminary study. Forensic Science International 118:29-35. DOI: 10.1016/S03790738(00)00372-8.

Maile AE, Inoue CG, Barksdale LE, Carter DO. 2017. Toward a universal equation to estimate postmortem interval. Forensic Science International 272:150-153. DOI: 10.1016/j.forsciint.2017.01.013.

Muñoz Barús JI, Suárez-Peñaranda JM, Otero XL, Rodríguez-Calvo MS, Costas E, Miguéns X, Concheiro L. 2002. Improved estimation of postmortem interval based on differential 
570

571

572

573

574

575

576

577

578

579

580

581

582

583

584

585

586

587

588

589

590

591

592

593

594

595

596

597

598

599

600

601

602

603

604

605

606

607

608

609

610

611

612

613

614

615

behaviour of vitreous potassium and hypoxantine in death by hanging. Forensic Science International 125:67-74. DOI: 10.1016/S0379-0738(01)00616-8.

Na J-Y. 2020. Estimation of the post-mortem interval using microRNA in the bones. Journal of Forensic and Legal Medicine 75:102049. DOI: 10.1016/j.jflm.2020.102049.

Nagy C, Maheu M, Lopez JP, Vaillancourt K, Cruceanu C, Gross JA, Arnovitz M, Mechawar N, Turecki G. 2015. Effects of Postmortem Interval on Biomolecule Integrity in the Brain. Journal of Neuropathology \& Experimental Neurology 74:459-469. DOI: 10.1097/NEN.0000000000000190.

Paraskevopoulou MD, Georgakilas G, Kostoulas N, Vlachos IS, Vergoulis T, Reczko M, Filippidis C, Dalamagas T, Hatzigeorgiou AG. 2013. DIANA-microT web server v5.0: service integration into miRNA functional analysis workflows. Nucleic Acids Research 41:W169-W173. DOI: 10.1093/nar/gkt393.

Pozhitkov AE, Neme R, Domazet-Lošo T, Leroux BG, Soni S, Tautz D, Noble PA. 2017. Tracing the dynamics of gene transcripts after organismal death. Open Biology 7:160267. DOI: $10.1098 /$ rsob.160267.

Reczko M, Maragkakis M, Alexiou P, Grosse I, Hatzigeorgiou AG. 2012. Functional microRNA targets in protein coding sequences. Bioinformatics 28:771-776. DOI: 10.1093/bioinformatics/bts043.

Sanoudou D, Kang PB, Haslett JN, Han M, Kunkel LM, Beggs AH. 2004. Transcriptional profile of postmortem skeletal muscle. Physiological Genomics 16:222-228. DOI: 10.1152/physiolgenomics.00137.2003.

Tomita Y, Nihira M, Ohno Y, Sato S. 2004. Ultrastructural changes during in situ early postmortem autolysis in kidney, pancreas, liver, heart and skeletal muscle of rats. Legal Medicine 6:25-31. DOI: 10.1016/j.legalmed.2003.09.001.

Tu C, Du T, Ye X, Shao C, Xie J, Shen Y. 2019. Using miRNAs and circRNAs to estimate PMI in advanced stage. Legal Medicine 38:51-57. DOI: 10.1016/j.legalmed.2019.04.002.

Vishnoi A, Rani S. 2017. MiRNA Biogenesis and Regulation of Diseases: An Overview. In: Methods in Molecular Biology. 1-10. DOI: 10.1007/978-1-4939-6524-3_1.

Wang H, Mao J, Li Y, Luo H, Wu J, Liao M, Liang W, Zhang L. 2013. 5 miRNA expression analyze in post-mortem interval (PMI) within 48h. Forensic Science International: Genetics Supplement Series 4:e190-e191. DOI: 10.1016/j.fsigss.2013.10.098.

Zhang H, Devoucoux M, Song X, Li L, Ayaz G, Cheng H, Tempel W, Dong C, Loppnau P, Côté J, Min J. 2020. Structural Basis for EPC1-Mediated Recruitment of MBTD1 into the NuA4/TIP60 Acetyltransferase Complex. Cell Reports 30:3996-4002.e4. DOI: 10.1016/j.celrep.2020.03.003.

Zhou W, Xu J, Wang C, Shi D, Yan Q. 2019. miR-23b-3p regulates apoptosis and autophagy via suppressing SIRT1 in lens epithelial cells. Journal of Cellular Biochemistry 120:1963519646. DOI: $10.1002 /$ jcb.29270.

Zhu R, Li X, Ma Y. 2019. miR-23b-3p suppressing PGC1 $\alpha$ promotes proliferation through reprogramming metabolism in osteosarcoma. Cell Death \& Disease 10:381. DOI: 10.1038/s41419-019-1614-1.

Zhu Y, Wang L, Yin Y, Yang E. 2017. Systematic analysis of gene expression patterns associated with postmortem interval in human tissues. Scientific Reports 7:5435. DOI: 10.1038/s41598-017-05882-0.

Zilg B, Bernard S, Alkass K, Berg S, Druid H. 2015. A new model for the estimation of time of death from vitreous potassium levels corrected for age and temperature. Forensic Science 
616 International 254:158-166. DOI: 10.1016/j.forsciint.2015.07.020.

617 


\section{Table $\mathbf{1}$ (on next page)}

Presence of the external and internal macroscopic morphological characteristics in rats at different post-mortem intervals. 
1 Table 1. Presence of the external and internal macroscopic morphological characteristics

2 in rats at different post-mortem intervals.

\begin{tabular}{llllll}
\hline & \multicolumn{5}{c}{ Frequency $\mathbf{~}$} \\
\cline { 2 - 5 } Morphological Changes & $\mathbf{0}$ h-PMI & $\mathbf{3}$ h-PMI & $\mathbf{6}$ h-PMI & $\mathbf{1 2}$ h-PMI & $\mathbf{2 4}$ h-PMI \\
\hline External & 0 & 100 & 100 & 100 & 100 \\
Algor mortis (AM) & 0 & 100 & 100 & 100 & 100 \\
Livor mortis (LM) & 0 & 100 & 100 & 0 & 0 \\
Rigor mortis upper body (RMU) & 0 & 0 & 100 & 100 & 0 \\
Rigor mortis lower body (RML) & 0 & 100 & 100 & 100 & 100 \\
Drying (DR) & 0 & 0 & 100 & 100 & 100 \\
Generalized Edema (ED) & 0 & 100 & 100 & 100 & 100 \\
Hair loss (HL) & 0 & 0 & 0 & 40 & 100 \\
Abdomen green discoloration (AGD) & 0 & 100 & 100 & 100 & 100 \\
Abdominal distention (AD) & & & & & \\
Internal & & & & & \\
Brain liquefaction (BL) & 0 & 40 & 60 & 100 & 100 \\
Brain edema (CE) & 0 & 20 & 100 & 100 & 100 \\
Discoloration of liver (DL) & 0 & 60 & 80 & 100 & 100 \\
Loss liver consistency (LLC) & 0 & 20 & 60 & 80 & 100 \\
Livor mortis muscle (LMM) & 0 & 60 & 60 & 100 & 100 \\
Bowel swelling (BS) & 0 & 20 & 100 & 100 & 100 \\
Ascites (AS) & 0 & 0 & 0 & 0 & 60 \\
Loss muscle consistency (LMC) & 0 & 0 & 0 & 0 & 80 \\
\hline
\end{tabular}

3

4

5

6

7

8

9 


\section{Figure 1}

Multiple correspondence analysis (MCA) between the early post-mortem interval and the presence of morphological changes in rats.

A) MCA of the analyzed PMIs (0, 3, 6, 12 and $24 \mathrm{~h})$ and the presence of internal and external morphological changes. B) MCA of the PMls groups I ( 0 and 3 h), II (6 and 12 h) and III (24 h), and the presence of internal and external morphological changes. Both plots represented the greatest cumulative variability and could capture at least the $74.2 \%$ of the data.

Abbreviations of the morphological characteristics are shown in Table 1. Dots represent each rat, while squares are the dichotomic presence of morphological changes (0: absence, 1 : presence). The dashed line ellipses shown the distribution of the rats throughout the PMI.

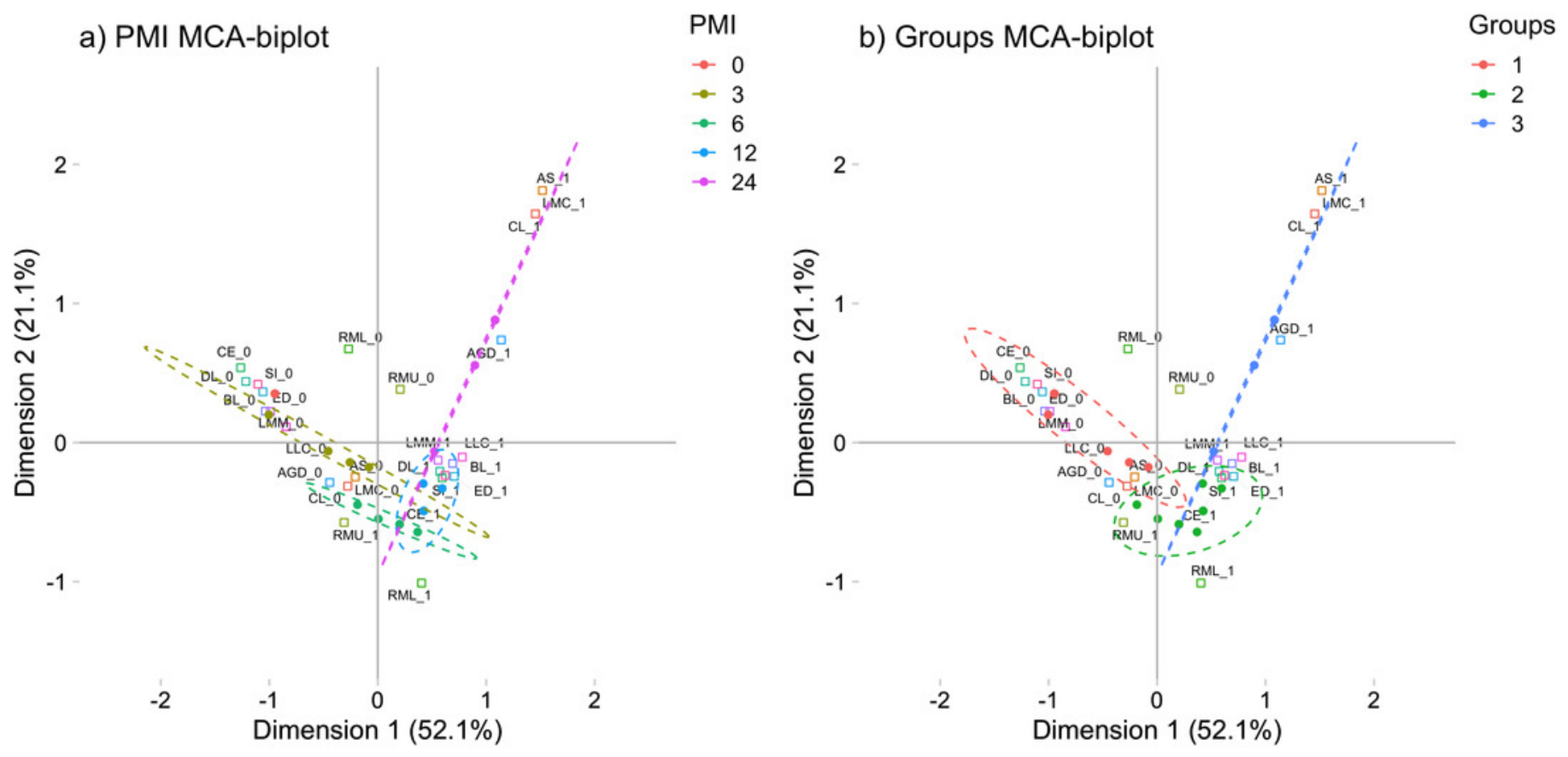




\section{Figure 2}

Gene expression analysis of miRNAs miR-381-3p, miR-23b-3p and miR-144-3p in rat skeletal muscle throughout the early different post-mortem interval.

The Fold-Change (FC) of miRNAs A). miR-381-3p B). miR-23b-3p and C). miR-144-3p was analyzed in rats skeletal muscle at $0,3,6,12$ and 24 hours of PMI using quantitative RTqPCR. The Fold Change of each miRNA was calculated with the $2^{-\mathbf{A \Lambda C T}}$ method using miR-361-5p as internal control. The black squares represent the mean of the FC from each group, the whisker corresponds to the 95\% confidence interval and the dots are the jittered FC of each sample. Comparisons between the PMI were done with the Mann U- Whitney test. $*$ p-value $<0.05, * *$-value $<0.01$

a) $\mathrm{miR}-381-3 p$

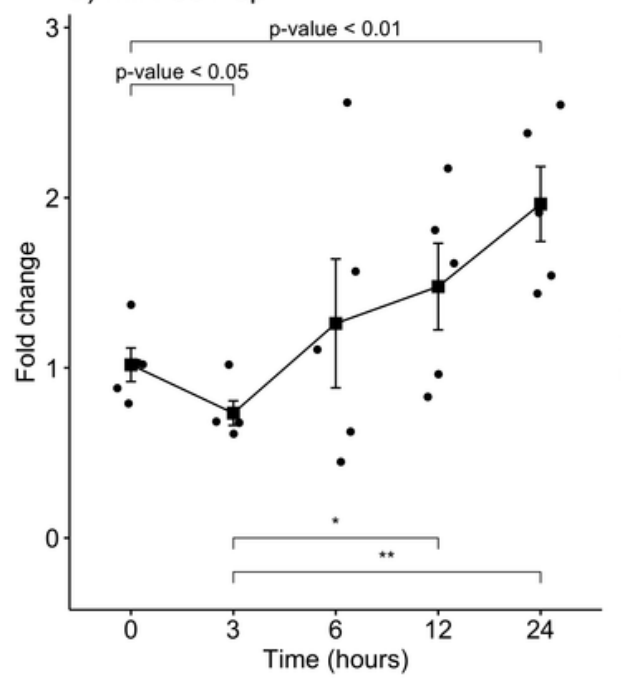

b) $\mathrm{miR}-23 \mathrm{~b}-3 \mathrm{p}$

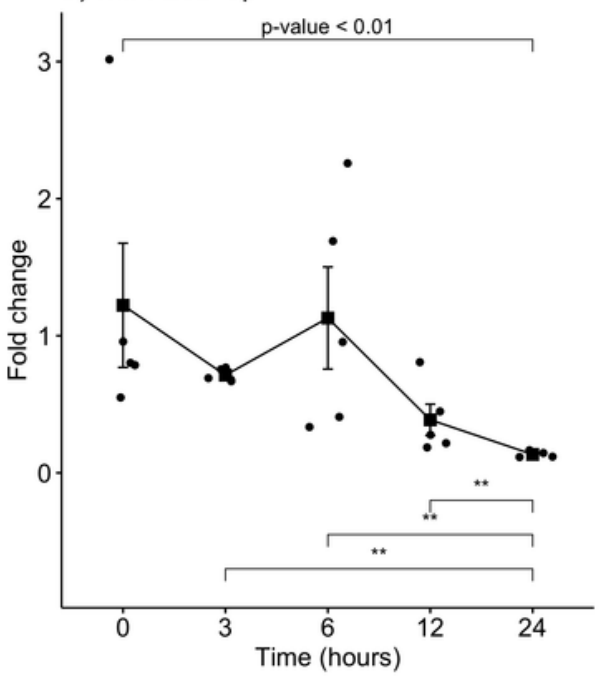

c) $m i R-144-3 p$

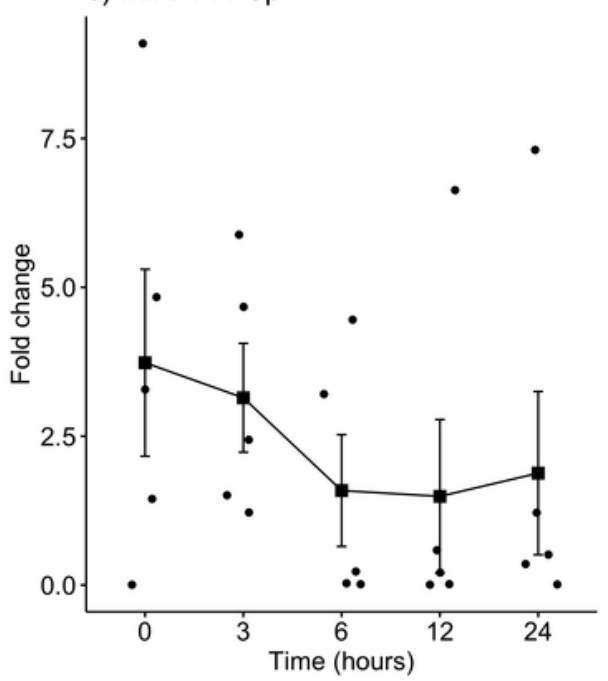


Figure 3

Gene Ontology enrichment analysis.

The main biological pathways where the target genes of miRNAs A) miR- 381-3p and B) miR-23b-3p participate are shown. The $x$-axis correspond to the enrichment ratio and all the biological pathways have a False Discovery rate less than 0.05 .

a) $\operatorname{miR}-381-3 p$

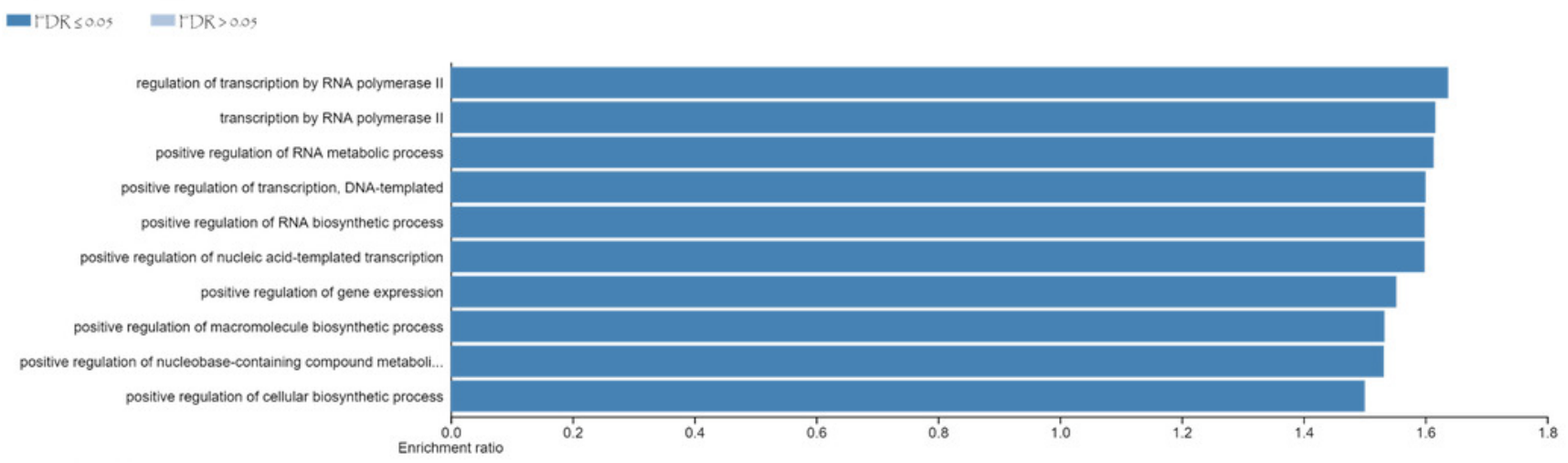

b) $\mathrm{miR}-23 \mathrm{~b}-3 \mathrm{p}$

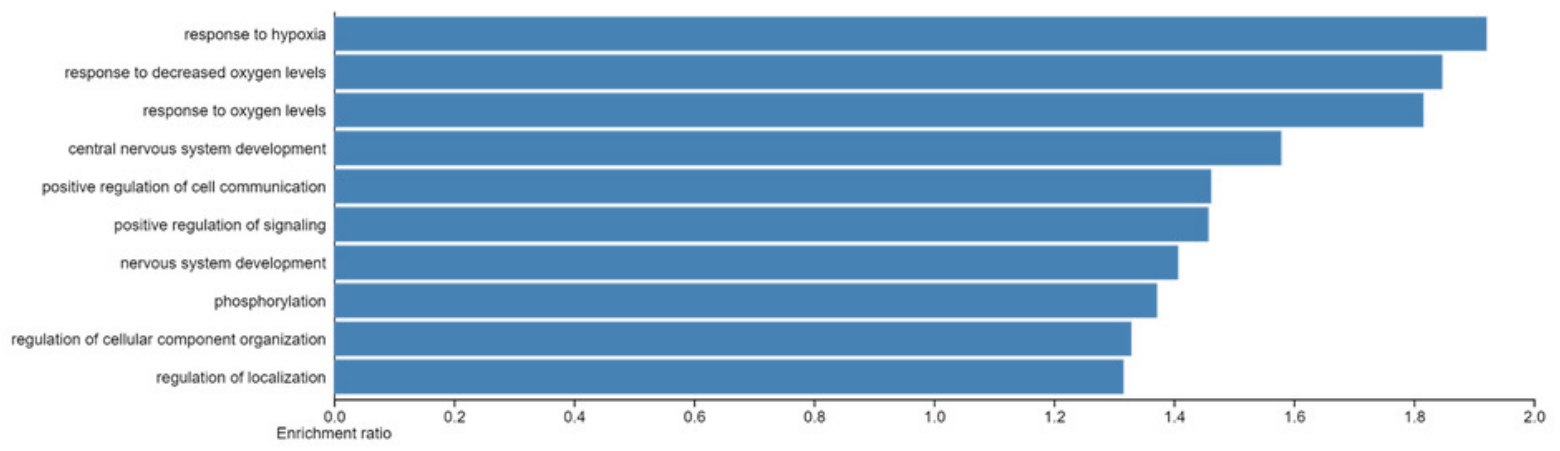




\section{Figure 4}

Gene expression analysis of EPC1 gene in rat skeletal muscle at early post-mortem interval.

The Fold-Change (FC) of EPC1 was analyzed in rats skeletal muscle at 3, 6, 12 and 24 hours of PMI relatively to the $0 \mathrm{~h}$-PMI group, using quantitative RT-qPCR. The Fold Change was calculated with the $2^{-\mathbf{\Lambda \Lambda C T}}$ method using as internal control. The black squares represent the mean of the FC from each group, the whisker corresponds to the $95 \%$ confidence interval and the dots are the jittered FC of each sample. Comparisons between the PMI were done with the Mann U- Whitney test. * p-value $<0.05, * *$-value $<0.01$ 


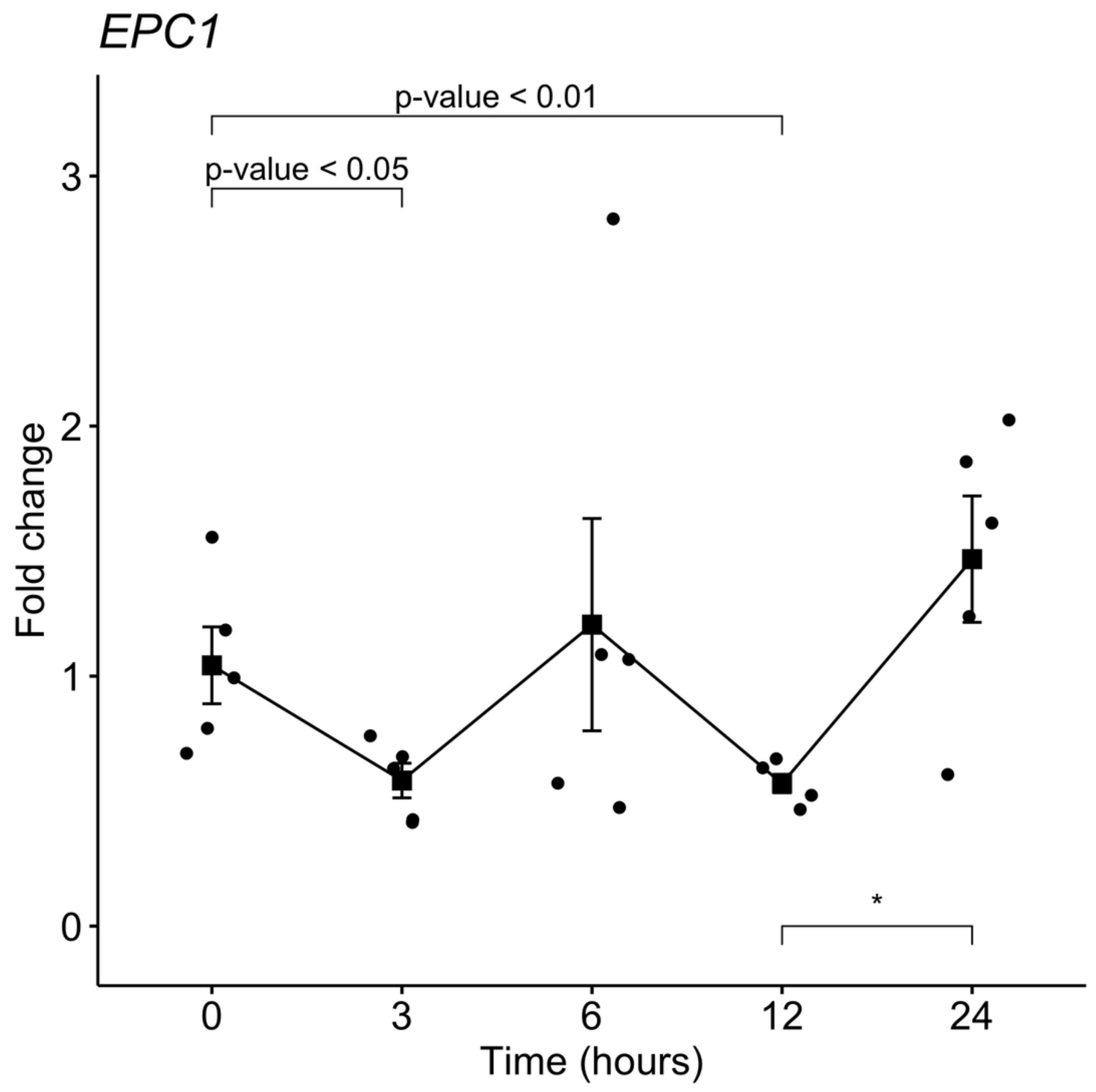

